\title{
AVALIAÇÃO DA CABOTAGEM COMO UM MODAL DE TRANSPORTE
}

Michel Mensinger Rocumback ${ }^{1}$ Luiz M de Niemeyer Neto ${ }^{2}$

\section{RESUMO}

O objetivo do artigo é analisar os diferentes meios de transporte utilizados no Brasil, ou seja, analisar a atual infraestrutura do país e indicar onde futuros investimentos poderiam ser alocados. A hipótese que queremos desenvolver é a de que atualmente no Brasil o sistema rodoviário é o mais utilizado e financiado pelo governo, contudo no sentido vertical a cabotagem é o modal mais vantajoso economicamente, inclusive mais vantajosa até do que o sistema ferroviário.

Palavras-chave: Transportes; Cabotagem; Planejamento; Infraestrutura; Políticas Públicas.

\section{INTRODUÇÃO}

O objetivo deste artigo é analisar os diferentes meios de transporte de carga utilizados no Brasil, a fim de, questionar a atual infraestrutura do país e indicar onde futuros investimentos devem ser alocados. Nossa hipótese é que atualmente no Brasil o sistema rodoviário é o mais utilizado e financiado pelo governo.

1 Professor da Pontifícia Universidade Católica de São Paulo.

2 Professor da Pontifícia Universidade Católica de São Paulo. 
Contudo no sentido vertical a cabotagem é o modal mais vantajoso economicamente, inclusive mais vantajosa até do que o sistema ferroviário.

Esse trabalho buscará elucidar qual dos modais deve ser foco de investimento no país, visando maximizar a produtividade e reduzindo custos, tornando o país mais competitivo, iniciaremos com a premissa de que o modal rodoviário recebe uma atenção muito maior do que o necessário, deixando na penumbra os modais ferroviários e a cabotagem. Isto, por sua vez, reforça os gargalos em infraestrutura e logística no país. A ideia aqui não é apontar qual o modal mais indicado. Exemplificando, apesar do modal ferroviário ter sido um dos pilares para o desenvolvimento de diversos países, talvez esse não seja o caso do Brasil, pois o país se destaca pelo seu vasto litoral e daí darmos uma atenção especial para a cabotagem.

Sendo assim, identificamos que um dos gargalos para o desenvolvimento do país é a fraca infraestrutura nos modais de transporte. Portanto, antes de se começar a investir em qualquer um dos modais, temos que saber qual dos modais possui um maior custo benefício para o país na atualidade. Em seguida temos que analisar se realmente esse modal é aquele que deve ser privilegiado com os investimentos públicos. Cada país possui uma preferência por um tipo de modal, baseado na economia do país e nos aspectos geográficos.

$\mathrm{Na}$ seção 2 discutimos os diferentes modais. Na seção 3 discutimos a cabotagem como melhor modal no sentido vertical. Finalmente, apresentaremos nossas conclusôes.

\section{OS DIFERENTES MODAIS}

Nessa seção vamos entender um pouco sobre o planejamento da infraestrutura e logística de nosso país. Para isso utilizaremos dados o governo para poder deslumbrar um pouco a percepção deles quanto as necessidades do país acerca do desenvolvimento dos modais. Para começar nossa análise primeiramente temos que entender como o país está se planejando para o futuro. Partindo dessa visão logo de início é possível afirmar que o sistema privilegiado no Brasil é o sistema rodoviário. Nas Figuras 1 e 2 são demonstrados quais projetos tem custos contemplados pelo PAC assim como a extensão, quantidade e investimento dos projetos avaliados de cada modal. 
Figura 1 Percentual de custos de projetos de projetos pertencentes ou não ao PAC.

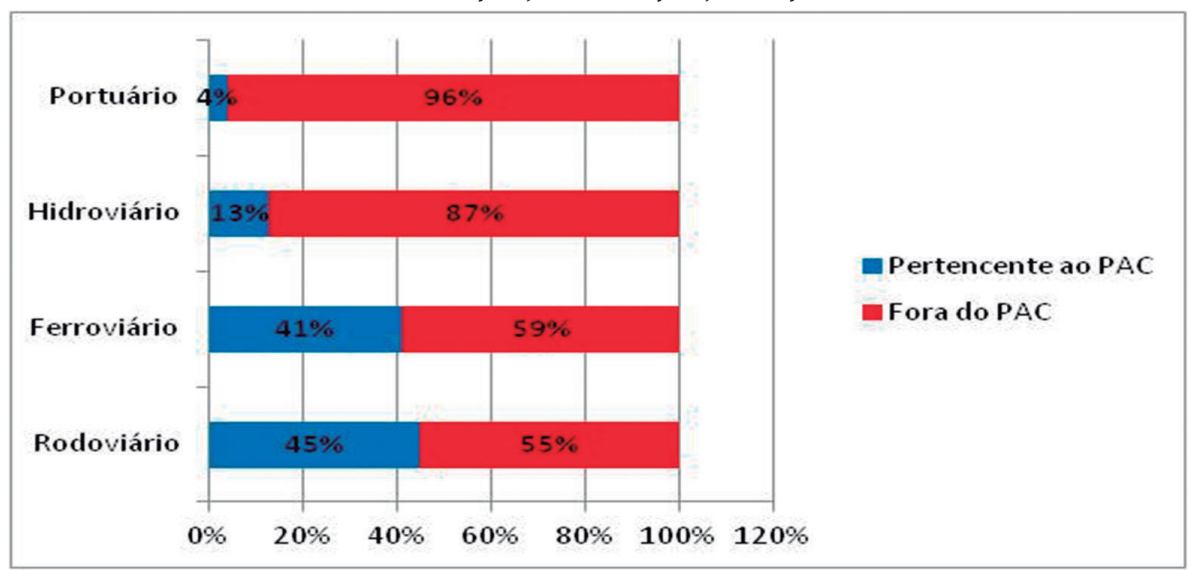

Fonte: Ministério dos Transportes (2014, p. 182).

A Figura 1 indica que o sistema rodoviário é o modal preferencial, contudo o número de projetos suportados pelo PAC desse modal é quase igual ao do sistema ferroviário, ao mesmo tempo, essa figura nos evidencia que há um abandono dos portos e hidrovias que engloba o modal da cabotagem.

Figura 2 Percentual de projetos avaliados por modal.

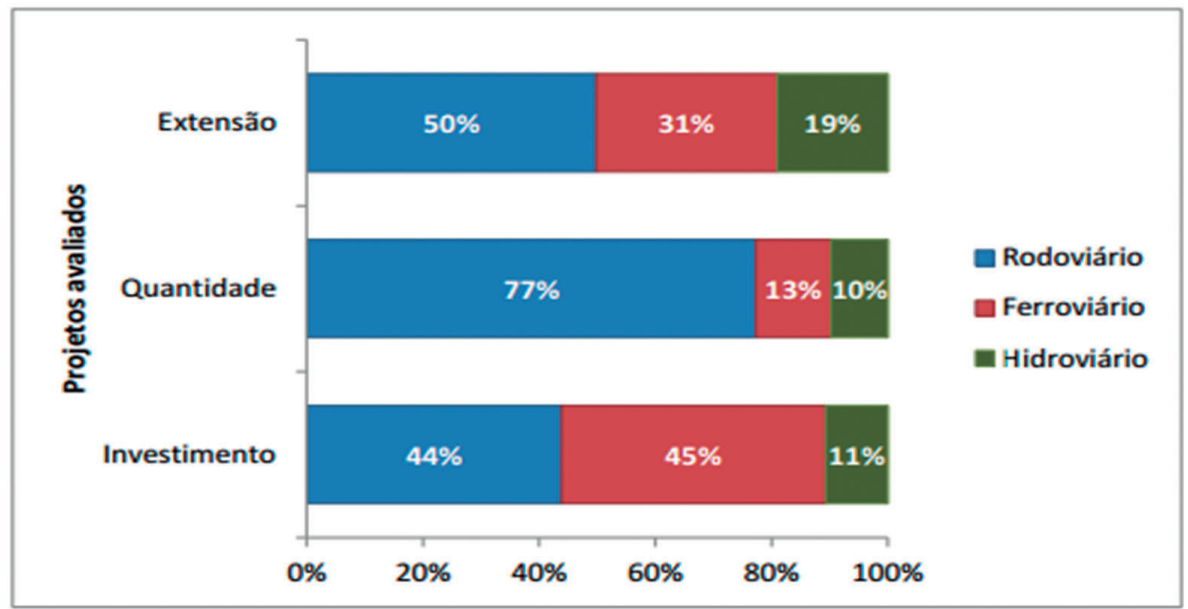

Fonte: Ministério dos Transportes (2014, p. 194).

A Figura 2 deixa ainda mais nítido esse descaso com os sistemas ferroviários e de cabotagem. Fica claro que há um interesse muito maior do Estado em desenvolver as rodovias do que qualquer outro meio de transporte. Isso faz com que o modal rodoviário tenha quase 80 por cento dos projetos avaliados, enquanto os demais juntos não chegam nem a 25 por cento. Contudo nessas duas análises vemos que o 
setor hidroviário é claramente deixado de lado, não obtendo nem ao menos 15 por cento dos investimentos ou quantidades de projetos.

Além dos dados relacionados ao investimento nos modais também é interessante analisar o LPI (índice de performance logística) do Brasil. Esse índice leva em consideração 6 fatores: pontualidade; rastreamento e localização; competência logística; competitividade dos preços; eficiência do processo; e infraestrutura.

A Figura 3 nos permite ver que países desenvolvidos possuem um LPI elevado, tendo o indicador acima de 3.5. Ao mesmo tempo os países em desenvolvimento (Rússia, Brasil, Índia e China) ainda não ultrapassam esse ponto, tirando a China que se destaca como principal potência em crescimento, os demais participantes do BRICS não chegam a alcançar nem ao menos o marcador 3 desse índice.

Figura 3 Índice de performance logística comparando alguns países.

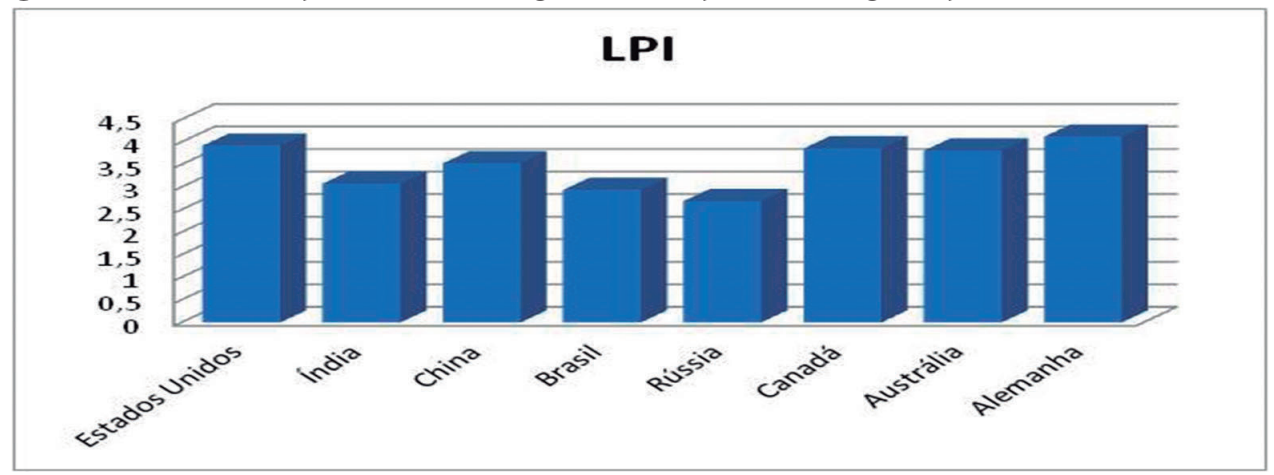

Fonte: World Bank, 2014, dados compilados pelos autores.

Para analisar melhor o caso do Brasil, podemos analisar a Figura 4, onde podemos ver as notas de cada um dos segmentos do LPI. Desse modo é visível que os principais gargalos logísticos do país são: Eficiência do Processo; Competitividade dos preços e Infraestrutura.

Esses itens do LPI podem melhorar se o governo aumentar o investimento em infraestrutura de modo a otimizar os modais. Isto faria que o país tenha preços mais competitivos e perca menos produtos ao longo do transporte como é o caso dos grãos. Vale ressalvar essa questão, pois os custos com transporte representam até mais que 50 por cento dos custos logísticos. Podem chegar a até 74 por cento no caso das empresas automotivas. A 65 por cento no setor de alimentos, farmácia, higiene e fumo. A 68 por cento no setor químico, petroquímico. A 63 por cento no setor da siderurgia, metalurgia e mineração. A 40 por cento no setor de tecnologia, computação e eletrônico. (REBELO, 2011) 
Figura 4 Índice de performance logística do Brasil.

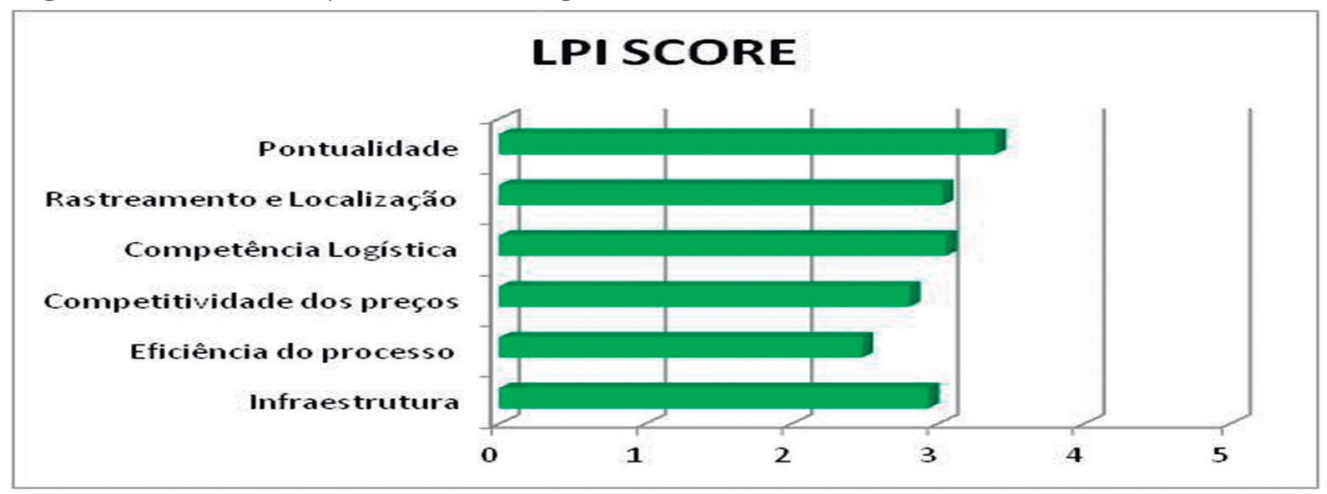

Fonte: World Bank, 2014, dados compilados pelos autores.

Por fim temos que o custo logístico no Brasil é entre 10 e 15\% do PIB sendo muito maior do que em outros países como EUA. Ao mesmo tempo os investimentos no Ministério dos Transportes não ultrapassam 1 por cento do PIB, tendo assim um investimento muito menor do que ocorre em outros países do mesmo porte. (REBELO, 2011).

\subsection{Modal rodoviário}

O Brasil, como podemos observar na Figura 5, utiliza principalmente o transporte rodoviário. Isso se deve a certa influência norte-americana que possuía uma indústria automobilística forte e utilizava desse segmento industrial para alavancar a economia devido ao seu alto grau de encadeamento produtivo.

Figura 5 Porcentagem da utilização dos modais no Brasil.

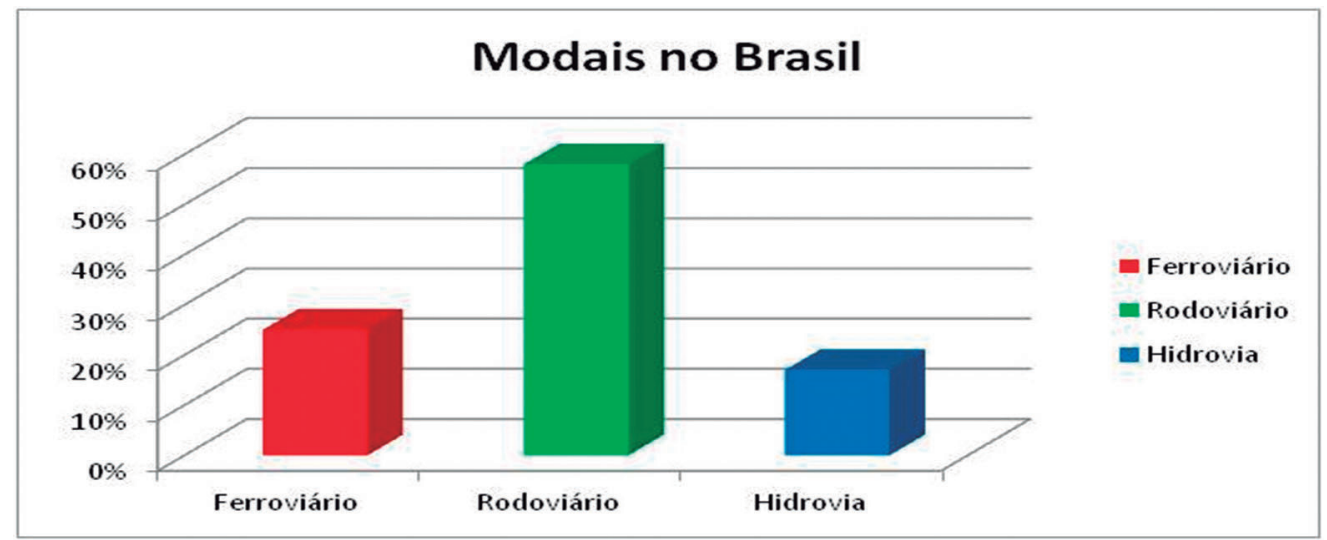

Fonte: Ministério dos Transportes (2014, p. 25), dados compilados pelos autores. 
O modal rodoviário foi desenvolvido no Brasil, sobretudo a partir do governo de Juscelino Kubitscheck quando o presidente através de incentivos e novas políticas trouxe diversas montadoras para o país. Com isso ocorreu desenvolvimento de rodovias que ligariam o país através de uma extensa malha rodoviária com cerca de 1,6 milhão de quilômetros de estradas, sendo capaz de ligar todos os Estados do país.

O sistema rodoviário passou então a alcançar lugares onde a cabotagem não seria capaz de alcançar. Ao mesmo tempo possuía um baixo custo de implementação e uma velocidade moderada. E, além disso, esse modal entregava produtos em um prazo inferior ao da cabotagem. Com essas vantagens e com o "boom" da indústria automobilística o governo passou a incentivar mais esse sistema, tendo em vista também que esse modelo de indústria é um modelo de alto encadeamento estrutural. Ou seja, ao investir no sistema automobilístico outras indústrias de base também passam a se desenvolver, gerando mais empregos e aquecendo a economia. (SILVA, 2016)

$\mathrm{Na}$ Figura 6 podemos ver que comparado a grandes países o Brasil possui uma grande malha rodoviário, superando a Rússia, Canadá, Austrália e até Alemanha. Além de possuir em números totais um sistema rodoviário mais abrangente, se considerarmos a dimensão de cada país.

Figura 6 Quantidades de estradas construídas (KM).

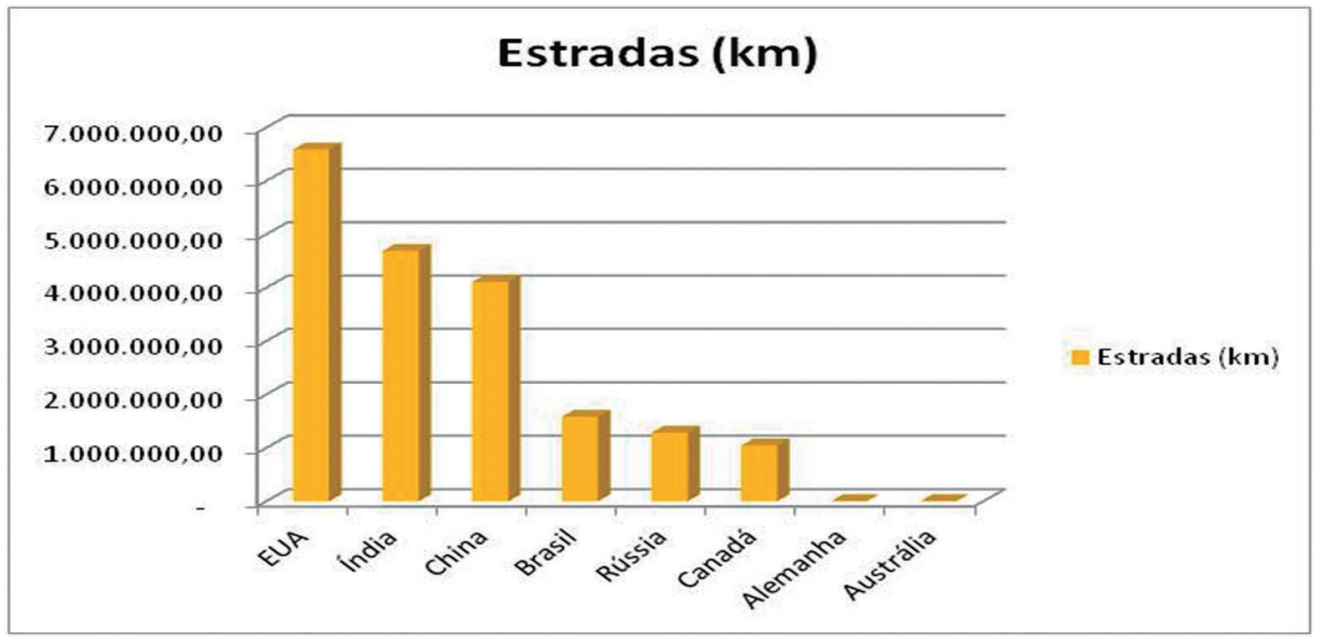

Fonte: CIA World Factbook, 2014, dados compilados pelos autores.

Sendo assim, temos um modal que movimenta $2 / 3$ das cargas do país, tendo um faturamento próximo de $\mathrm{R} \$ 40$ bilhōes. Este, por sua vez, não é concentrado, uma vez que, esse negócio não possui barreiras à entrada e possui um custo inicial 
baixo, de modo que pequenos proprietários podem participar desse modal. Isto torna o negócio muito pulverizado, e como constatado anteriormente, mesmo sendo o modal priorizado pelos investimentos do governo, a sua infraestrutura é muito debilitada. Isto acarreta um aumento do preço do serviço, devido aos gastos em reparos tanto por parte das empresas como por parte do governo que precisa constantemente reparar as vias. (LIMA, 2005)

Somado ao acima, o modal rodoviário apresenta outras características que fazem com que esse seja questionado como principal transporte logístico do país. Esse questionamento envolveria poluição, capacidade de carga e dificuldade de transportar cargas perecíveis.

O modal rodoviário é o mais poluente dos três. Contando com uma ampla frota de caminhões antigos e um consumo muito superior de gasolina se comparado aos demais modais. Ele consome 250 por cento de combustível a mais do que os trens e 375 por cento a mais do que os navios. Isso o torna o modal mais poluente do país. Ele também se torna mais questionado no Brasil do que nos demais países devido à baixa qualidade do diesel utilizado no país tendo uma maior liberação de gás carbônico e de enxofre.

Outra característica negativa desse modal é que ele também conta com uma pequena capacidade carga se comparado aos demais modais. Um navio é capaz de carregar 6 mil toneladas. Para a mesma quantidade ser transportada pelo modal ferroviário seriam necessários 86 vagóes de 70 toneladas (Comboio Hooper). Para o modal rodoviário carregar essa mesma carga seriam necessárias 172 carretas de 35 toneladas (Bi-trem graneleiras)

- Por fim, o sistema rodoviário também sofre dificuldades com produtos perecíveis. Esses tipos de alimento necessitam de um transporte muito rápido e refrigeração para não estragar. Isto faz com que parte desses produtos transportados por caminhões sejam perdido ao longo da viagem devido a longas viagens ou a difícil preservação do produto. É diferente, por exemplo, do que ocorre no modal da cabotagem, onde os containers reefers permitem o transporte desse tipo de produto. (BALLAN, 2009)

\subsection{Modal Ferroviário}

O modal ferroviário foi um dos principais alicerces do desenvolvimento de diversos países desenvolvidos como Alemanha. Esse sistema ligava as áreas produtoras de matéria prima até as grandes indústrias, interligando também toda a Europa 
facilitando a locomoção das pessoas dentro do continente. Isso aproximava diversos países e impulsionava a economia ao ligar de maneira mais rápida as indústrias às zonas de matérias-primas, revolucionando assim a produção alemã.

Além da Alemanha outros países que também se apoiaram no sistema ferroviário foram aqueles com territórios de grandes dimensões como Canadá, EUA, Rússia e China, uma vez que, a extensão desses países poderia dificultar o transporte de cargas pesadas. Contudo através desse sistema foi possível ligar esses países de leste a oeste, integrando assim essas nações e dinamizando as suas economias. Um exemplo disso foi a construção das transcontinentais nos Estados Unidos que serviram para ligar o país de leste a oeste, através da ideia de encurtar o caminho do pacífico até o atlântico.

No caso da Rússia as ferrovias se tornaram de grande importância, pois o Estado russo percebeu a importância militar e econômica do modal, uma vez que, seria a forma mais rápida para transportar soldados e permitia uma aproximação das zonas indústrias as matérias primas, além disso, esse modal também permite levar mercadorias para todas as regiōes do país, inclusive as mais distantes, como podemos ver com a ferrovia transiberiana que é a maior ferrovia do mundo com $9.259 \mathrm{~km}$. (MOSSÉ, 2015)

Porém, no Brasil o principal uso da ferrovia se dá ao transporte de materiais para a exportação, como podemos observar no trecho a seguir:

Nos requerimentos totais do modal ferroviário constata-se a predominância de setores tradicionais no uso do próprio modal para a realização das suas exportações, como os setores que produzem minério de ferro, aço ou aqueles que produzem cereais e sementes, grãos e frutos oleaginosos para exportação no Brasil. (BETARELLI JUNIOR, BASTOS e PEROBELLI, 2011)

Dessa forma, podemos ver que o modal ferroviário não é utilizado para transporte de mercadorias industrializadas ou manufaturas, tão pouco para a locomoção urbana. Além disso, a malha ferroviária tem uma pequena extensão se comparado a diversos países de grandes proporçôes territoriais (como podemos ver na Figura 7), sobretudo no norte, nordeste e centro-oeste do país, ligando assim poucos estados do país. Adicionalmente esse modal conta com um alto custo de implementação e uma velocidade lenta de entrega devido às dificuldades na carga e descarga do material.

Entretanto, esse sistema de transporte possui grande capacidade de carga, elevada eficiência energética, baixo custo de transporte, pequeno custo de manutenção, sendo também um modal pouco poluente. (MACIEL, 2007) 
Dessa forma o modal ferroviário se destaca como um modal de importância estratégica para o desenvolvimento do país superando o modal rodoviário e diversos quesitos. Contudo, devido ao alto custo de sua implementação, cerca de 4 vezes maior do que o modal rodoviário, isso torna tal modal pouco atrativo, uma vez que possui um custo muito elevado e um retorno a longo prazo. Isso tira a atratividade de investimento por parte do setor privado e até mesmo do governo.

Contudo, ainda sim esse modal é de extrema importância, pois vencida a barreira de entrada e construído as ferrovias ele passa a ser de grande eficiência. Adicionalmente ele atende o interior do país, região essa que a cabotagem não tem influência. Sendo assim, esse modelo deveria receber um investimento muito maior do que o que recebe na atualidade, pois o seu desenvolvimento é vital para a melhora logística do país.

Figura 7 Quantidades de ferrovias construídas (KM).

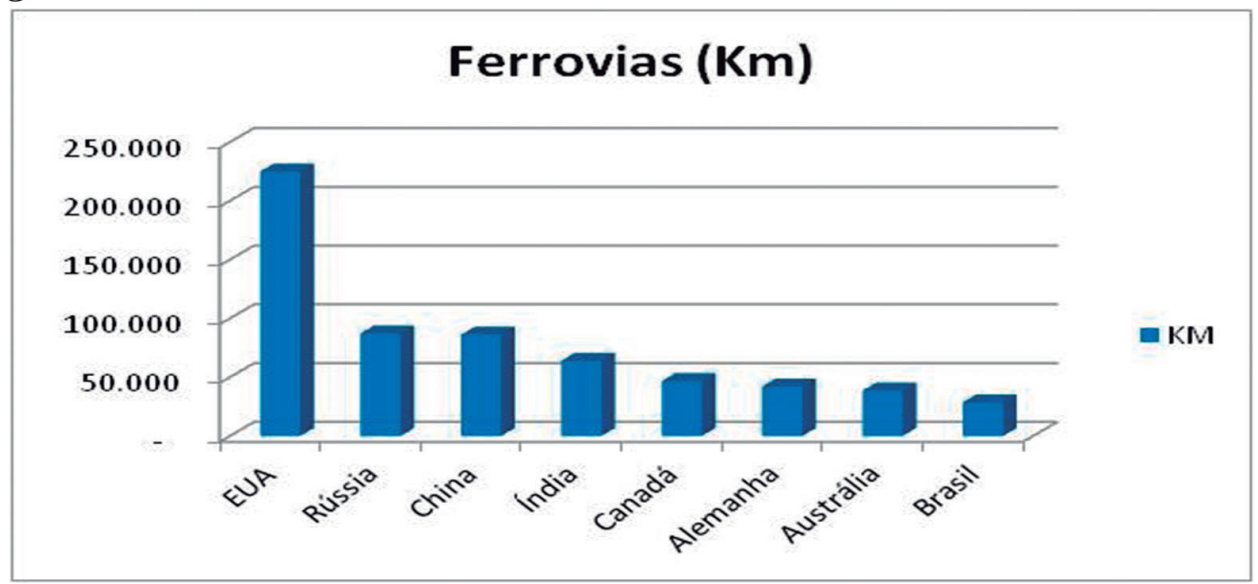

Fonte: CIA World Factbook, 2014, dados compilados pelos autores.

\subsection{Modal Cabotagem}

$\mathrm{Na}$ atualidade é evidente a importância da navegação para o desenvolvimento dos países, tanto que isso fez com que para proteger esse recurso econômico e estratégico alguns países adotassem certas medidas protecionistas como:

Nos Estados Unidos, a chamada "Jones Act" é uma lei federal de 1920 que regulamenta o transporte marítimo no país e tem por objetivo a promoção e manutenção da marinha mercante americana. Em sua "seção 27 " a Lei trata da cabotagem e exige que todas as mercadorias transportadas pela água entre os portos dos EUA o sejam em navios com bandeira dos EUA, construído nos EUA, de propriedade de cidadãos norte-americanos, e tripulados por cidadãos americanos ou residentes permanentes dos EUA. 
Já o Código do Transporte Marítimo Mercante da Federação Russa igualmente determina que a navegação entre portos no país esteja restrita a navios nacionais, porém atendendo a certos requisitos. Tanto o governo quanto a Federação Russa autorizam o transporte de cabotagem em navio de estrangeiro.

$\mathrm{Na}$ China, a legislação também é bastante restritiva, porém, recentemente, o governo adotou algumas medidas liberalizantes, visando o incremento dos transbordos dentro do território do país. No último dia 20 de abril, o Conselho de Estado da China liberou alguns terminais portuários a receber navios de bandeira estrangeira na movimentação de cargas domésticas. Uma das grandes expectativas dessa medida é de que o porto de Hong Kong (atualmente fora do alcance da regulamentação por se tratar de uma "Região Administrativa Especial") perca boa parte de sua movimentação portuária para os demais portos chineses, especialmente para Xangai. (BARRETO, 2016)

No Brasil o desenvolvimento desse modal foi não foi favorecido, uma vez que, o modal mais visado para investimentos do governo foi o rodoviário. Deixando assim os demais modais com pouco incentivo. Isso fez com que o desenvolvimento da cabotagem viesse acompanhado de gargalos estruturais, que impedem que esse sistema se desenvolva ainda mais e otimize seus resultados, tornando este modal menos atraente para seus clientes.

Segundo relatório do Banco Nacional de Desenvolvimento Econômico e Social (BNDES, 1997), em 1951, a navegação de cabotagem era responsável por 27,5 por cento da produção de transportes no Brasil. Desde que a indústria automobilística se desenvolveu no país, a partir da década de 50, a cabotagem jamais voltou a ser tão representativa quanto fora até então. Ao longo das décadas seguintes, sofreu grande diminuição de sua importância na matriz de transportes, atingindo seu ponto mínimo em 1994, quando respondeu por apenas 10 por cento da produção de transportes no país. Em 2002, este modal respondia por 14 por cento do total. (VACLAVIK; MAÇADA, 2009, p. 5)

Os gargalos da cabotagem se tornam visíveis ao se observar os portos. Esses não possuem estrutura capaz para atracar navios de grande porte como China, EUA ou Europa. Isso impede o modal de operar de maneira ótima, pois não será possível utilizar os maiores navios que transportam uma quantidade de carga muito mais elevada. Isto leva há um aumento do custo unitário no transporte de containers.

Somando-se ao acima, as empresas que realizam a cabotagem no Brasil têm de lidar com a superlotação de navios em portos. Ao mesmo tempo tem de lidar também com o monopólio de agentes portuários de algumas regiões. Esses aspec- 
tos fazem com que o negócio não consiga operar com seu custo mais competitivo. Atualmente no país nós vivemos em um período de elevado preço da gasolina, o que também eleva os custos desse modal.

Contudo, esse sistema conta com vantagens também, por exemplo, o fato do Brasil possuir $7.400 \mathrm{~km}$ de litoral e 80 por cento da população vivendo a cerca de $200 \mathrm{~km}$ da costa. Além disso, o transporte por cabotagem é mais barato, menos poluente, possui maior capacidade para transportar cargas e apresenta um menor número de roubos. Porém, mesmo com essas vantagens o sistema rodoviário continua sendo o seu maior concorrente, pegando uma parcela de transporte que seria melhor alocado no modal da cabotagem. (CIA World Factbook, 2015)

\section{CABOTAGEM O MELHOR MODAL NO SENTIDO VERTICAL ${ }^{3}$}

A cabotagem no Brasil é realizada por três empresas Aliança Navegação e Logística, Log-In e Mercosul-Line, sendo a primeira parte do grupo Hamburg Sud, que atualmente está em processo de aquisição pelo grupo Maersk Line, e a terceira parte o grupo Maersk Line.

A líder do market share no Brasil é a Aliança que possui aproximadamente 48 por cento do market, operando com dez navios, com capacidades que variam entre 3.800 TEUs $^{4}$ e 4.800 TEUs, tendo uma capacidade de 19.090, contudo a idade média da frota é de 18,4 anos. A operação da Aliança no Brasil se dá nos portos de: Manaus, Vila do Conde, Pecem, Suape, Salvador, Sepetiba, Santos, Itapoa, Imbituba, Rio Grande, Vitória.

Já a Log-In segue em segundo lugar no market share, tendo uma frota bem menor que a Aliança, tendo somente cinco navios com uma capacidade total de 11.400 TEUs com idade média de 3,4 anos, operando nos portos de: Manaus, Pecem, Suape, Salvador, Sepetiba, Santos, Itapoa, Imbituba, Rio Grande, Itapoa, Vitória, Navegantes, Fortaleza e Itaguai.

Por fim, em terceiro lugar nós temos Mercosul line operando com quatro navios, com uma capacidade total de 7.500 TEUs e 2,7 anos, atuando nos portos de:

3 Sentido vertical: Faz referência ao eixo Norte-Sul, não considerando o eixo leste-oeste.

4 TEUs: É uma unidade de medida padrãoutilizada para medir o volume dos containers. Twenty Foot Equivalent. 
Imbituba, Manaus, Paranaguá, Santos, Suape e Pecém, Itajai, Navegantes, Fortaleza, Salvador, Suape e Rio Grande.

Para realizar o transporte pela cabotagem é necessário saber quais são as principais taxas que esse modal emprega, sendo essas taxas o frete, a taxa de operação dos containers nos terminais portuários e demurrage. O frete é a principal taxa cobrada desse modal sendo responsável por cobrar o valor o transporte marítimo de um porto até outro porto. As taxas operacionais portuárias são referentes principalmente a movimentação dos containers do navio para o porto e vice-versa, por fim temos as taxas de demurrage as quais são referentes à cobrança da estadia do container por um período maior do que o acordado.

\subsection{Mercado de cabotagem no Brasil: comparações entre modais}

A cabotagem sozinha pode não ser o melhor modal para o país inteiro, uma vez que no sentido horizontal o modal ferroviário e rodoviário atinge melhor as necessidades do país, visto que, a cabotagem não tem condição para alcançar o interior o país. Sendo assim, analisaremos a cabotagem no sentido vertical onde para saber qual a melhor opção para se desenvolver no país irei analisar mais a fundo os seguintes aspectos: financeiro (gastos), fator ambiental, capacidade de carga e tempo de tramite da carga.

Observando a Figura 8 mostramos que o menor custo de transporte de uma tonelada por quilometro (TKU) é o de cabotagem, com o valor de US\$12,00 o segundo do modal ferroviário US\$18,00 e por último o do rodoviário US\$45,00. Analisando os dados citados acima também vemos então que os três modais possuem custos altos em comum: combustível, gasto com trabalhadores e manutenção. Ao entrar mais a fundo nesses dados vemos que apesar de serem gastos em comum há uma grande divergência dentro deles para cada modal. Tal diferença pode ser vista ao analisarmos os salários e gastos com pessoal isso ocorre, pois no sistema rodoviário é necessário um número muito maior de funcionários para entregar a mesma quantidade containers do que os outros serviços, já o modal ferroviário por sua vez apresenta um número menor, porém mesmo assim ainda é maior do que o da cabotagem. 
Figura 8 Quadro comparativo econômico os modais.

\begin{tabular}{|c|c|c|c|}
\hline Modal & Rodoviário & Ferroviário & Cabotagem \\
\hline Custo Fixo & Baixo & Elevado & Elevado \\
\hline Custo Variável & Elevado & Médio & Baixo \\
\hline $\begin{array}{l}\text { Consumo de } \\
\text { combustível } \\
\text { para } \\
\text { transportar } \\
\text { uma tonelada } \\
\text { por um } \\
\text { quilômetro }\end{array}$ & 4 litros & 6 litros & 15 litros \\
\hline $\begin{array}{l}\text { Custo em } \\
\text { destaque }\end{array}$ & $\begin{array}{l}\text { Motorista (16 por cento), } \\
\text { veículos (19 por cento), } \\
\text { pneus ( } 11 \text { por cento), } \\
\text { overhead ( } 14 \text { por cento), } \\
\text { combustíveis ( } 26 \text { por } \\
\text { cento), manutenção (14 } \\
\text { por cento) }\end{array}$ & $\begin{array}{l}\text { Gastos com pessoal, } \\
\text { combustíveis e lubrifi- } \\
\text { cantes, terminal, linha e } \\
\text { material rodante. }\end{array}$ & $\begin{array}{l}\text { Custo do armador: tripu- } \\
\text { lação ( } 20 \text { por cento }-27 \\
\text { por cento), manutenção e } \\
\text { reparos ( } 9 \text { por cento - } 11 \\
\text { por cento) e suprimentos e } \\
\text { seguros } \\
\text { Custo de viagem: combus- } \\
\text { tível ( } 35 \text { por cento - } 50 \text { por } \\
\text { cento), praticagem ( } 9 \text { por } \\
\text { cento - } 22 \text { por cento) e re- } \\
\text { bocador ( } 2 \text { por cento - } 3 \\
\text { por cento) Custos exter- } \\
\text { nos: portos e infraestrutu- } \\
\text { ra documentação e regula- } \\
\text { mentação, políticas para o } \\
\text { setor }\end{array}$ \\
\hline $\begin{array}{l}\text { US\$/ } \\
1000 \text { TKU }^{5}\end{array}$ & 45 & 18 & 12 \\
\hline
\end{tabular}

Fontes: rodoviário (Araújo et al., 2014); ferroviário (Ipea, 2010); cabotagem (ANTAQ, 2009).

Em relação à manutenção o modal rodoviário também sai perdendo quando analisamos esses números, uma vez que devido às péssimas condições das estradas no Brasil esse acaba sendo o modal que mais sofre, tendo assim um elevado custo com manutenções.

5 TKU: Transporte de 1 ton a $1 \mathrm{KM}$ 
Por fim temos a relação com o principal custo dos modais: o combustível. Esse quesito que é o mais importante nos estudos dos gastos do setor de transportes também é o que apresenta maior disparidade. Isso ocorre, pois para transportar uma tonelada por um quilômetro, a cabotagem utiliza apenas 4 litros de combustível, enquanto que o modal ferroviário utiliza já 50 por cento a mais de combustível e o modal rodoviário utiliza 275 por cento a mais de combustível. Portanto, o modal rodoviário é o mais suscetível às variações no preço dessa commodity e eleva o preço dos fretes, tirando assim grande parte da competitividade desse modal. (ANTAQ, 2009, p. 82)

Dessa forma, vemos que por uma análise de custo a cabotagem é o modal que menos sofre com isso. Grande parte disso se deve a capacidade de carga do modal o que permite que o mesmo possa diluir seus custos. Cada viagem desse modal atinge uma proporção absurdamente maior de clientes do que os demais modais, tornando o negócio menos custoso. Além disso, a cabotagem ainda conta com um fator de ser o modal mais seguro para se transportar cargas. (ANTAQ, 2009.)

Portanto, sob a ótica dos custos a cabotagem seria o modal mais vantajoso. Porém também é importante ver a ótica pública para entender quais seriam os custos para se investir nesse modal. Nesse quesito vamos ver alguns impactos dos modais que interessam para o Estado, como por exemplo: o custo de manutenção, expansão, impacto ambiental e impacto logístico.

Ao avaliarmos o custo de manutenção e expansão para o Estado temos que novamente a cabotagem se destaca como melhor modal para se investir, isso ocorre, pois esse modal não precisa de investimentos estatais para desenvolver suas vias. O único investimento que esse modal necessita é o desenvolvimento os portos, onde grande parte os investimentos vêm de empresas privadas e cuja maior motivação é melhorar o fluxo de mercadorias para exportação e importação.

Já o modal rodoviário necessita de US\$440 mil para implementar 1 quilometro de rodovia, ao mesmo tempo o modal ferroviário necessita de US\$1,4 milhão para 1 quilometro de ferrovia, além disso fora o investimento inicial para criar esses caminhos o modal rodoviário e ferroviário ainda necessita de intensos investimentos para realizar a manutenção de suas vias e possuem um impacto menor nas exportações e importações do país. (SOARES, 2009, p. 12)

Em relação ao impacto ambiental hoje em dia considerado um fator importante por toda a população e pelo Estado destacamos a cabotagem como melhor opção. Esse modal é o menos poluente entre os três, pois a cabotagem produz 74 
gramas e monóxido de carbono para transportar uma tonelada por 1 quilômetro, enquanto que o transporte ferroviário produz 104 gramas para as mesmas proporções e o modal rodoviário se torna o mais poluente produzindo 219 gramas. (ANTAQ, 2009, p. 83)

Portanto, tanto sob a ótica do consumidor final quanto sob a ótica do Estado a cabotagem se mostra a melhor opção para transportar carga, uma vez que, seu grande potencial de carga torna o frete desse modal mais competitivo, menos poluente, com menor custo de manutenção e com um custo menor por container.

Contudo, vale ressaltar que infelizmente o transporte hidroviário só tem uma representatividade mais forte na costa (Cabotagem), e, portanto, esse seria o modal mais indicado para se fazer o transporte de carga no sentido vertical (eixo norte-sul). Porém para realizar o transporte no eixo horizontal o modal mais indicado seria o ferroviário, como é utilizado nos países desenvolvidos. Conforme as comparações já realizas nesse trabalho, o modal rodoviário é o menos indicado para qualquer transporte de carga caso haja uma das outras duas opçóes. Esse último apresenta o frete menos competitivo, é mais poluente e possui uma capacidade de transporte de carga muito baixa.

\section{CONCLUSÃ̃o}

Esse artigo teve o intuito de elucidar o fato de que a política atual brasileira não está otimizando os seus recursos. Estamos alocando muita verba e esforço no modal menos eficiente no sentido vertical (modal rodoviário). Isto faz com que as operações se tornem mais caras para os fabricantes. Esse custo elevado é em grande parte repassado para o consumidor final, tornando os produtos menos atrativos e mais caros.

É visível que o governo deve rever os seus planos da área logística, a fim de, tornar os produtos nacionais mais competitivos, e evitar perdas e avarias ao longo do percurso. Para isso é necessário desenvolver mais a cabotagem ao invés do modal rodoviário. É importante observar que dados desagregados especificamente sobre a cabotagem não estão atualizados. Todavia, quando sabemos de sua representatividade dentro do setor hidroviário podemos afirmar que este modal abrange a maior parte do hidroviário.

Como sugestão para melhorar a cabotagem sugiro começar com: menos burocratização do processo (em relação a necessidade de uma gama muito grande de 
documentos para realizar a cabotagem). Um investimento maior nos portos brasileiros, uma vez que, esses não apresentam uma estrutura competitiva em âmbito internacional.

A falta de competitividade se deve pela impossibilidade de atracação dos mais novos navios (que devido ao calado do navio não conseguem atracar em muitos portos brasileiros). Isso se deve a pouca divulgação e uso desse modal. O tamanho dos portos brasileiros que são pequenos se comparados ao de países desenvolvidos. Isto se deve ao fato dos terminais portuários operarem com uma tecnologia e investimento muito menor do que os europeus, chineses e norte-americanos. Logo, a operação portuária no Brasil se torna muito mais cara e menos eficiente, sendo imprescindível uma mudança nesse setor caso o país deseje crescer e se tornar uma potência econômica madura e forte internacionalmente.

\section{REFERÊNCIAS}

ANTAQ, TKU da navegação interior e de cabotagem - 2014, agosto de 2015. Disponível em:<http://web.antaq.gov.br/Portal/pdf/EstatisticaNavInterior/Transporte_de_Cargas_ Hidrovias_Brasileiras_2015TKU.pdf $>$. Acesso em: 19 de março de 2017.

ANTAQ, Panorama Aquaviário, março de 2009. Disponível em: <http://web.antaq.gov. $\mathrm{br} /$ Portal/pdf/PanoramaAquaviario3.pdf $>$. Acesso em: 19/03/2017.

BALLAN, Antonio I., novembro de 2011. Apresentação Caramuru Alimentos - "A HIDROVIA QUE GARANTE COMPETITIVIDADE E SUSTENTABILIDADE" $<$ http://portal.antaq.gov.br/wp-content/uploads/2016/12/A-Hidrovia-que-garanteCompetitividade-e-Sustentabilidade-Antonio-Ismael-Ballan.pdf>. Acesso em: 14/09/2016.

BARRETO, Leandro, A cabotagem no Mundo, agosto de 2016. <http://www.guiamaritimo. com.br/especiais/cabotagem/a-cabotagem-no-mundo >. Acesso em: 19 março de 2017.

BETARELli JUNIOR, A. A.; BASTOS, S. Q. A.; PEROBELli, F. S., Interações e encadeamentos setoriais com os modais de transporte: uma análise para diferentes destinos das exportações brasileiras, junho de $2011<$ http://www.scielo.br/scielo.php?script=sci_ar ttext\&pid=S141380502011000200004>. Acesso em: 14 de setembro de 2016.

BETARELLI JUNIOR, A. A., Análise dos modais de transporte pela ótica dos blocos comerciais: uma abordagem intersetorial de insumo-produto. Rio de Janeiro, Editoria BNDES, 2012.

CIA World Factbook, 01 de janeiro de 2014. Disponível em:<http://www.indexmundi. $\mathrm{com} / \mathrm{map} /$ ? $\mathrm{v}=113 \& \mathrm{l}=\mathrm{pt}>$. Acesso em: 19 de março de 2016.

INTERMODAL, 07 de abril de 2015. Disponível em: <http://www.antaq.gov.br/portal/ pdf/Palestras/2015/20150407-Fernando-Fonseca-Cabotagem-INTERMODAL-SPabril-2015.pdf>. Acesso em: 19 de março de 2016. 
MINISTÉRIO DO TRANSPORTE. Projeto de Reavaliação de Estimativas e Metas do PNLT, setembro de 2012. Disponível em: <http://www.transportes.gov.br/images/2014/11/ PNLT/2011.pdf>. Acesso em: 19 de março de 2016.

NARDES, Augusto. Desenvolvimento de infraestrutura de transportes no Brasil: Perspectivas e Desafios, janeiro de 2007. Disponível em: <http://portal.tcu.gov.br/ biblioteca-digital/desenvolvimento-de-infra-estrutura-de-transportes-no-brasilperspectivas-e-desafios-1.htm>. Acesso em: 04 de outubro de 2016.

REBELO, Jorge. Logística de Carga no Brasil, dezembro de 2011. Disponível em: <http:// siteresources.worldbank.org/BRAZILINPOREXTN/Resources/38171661323121030855/JorgeRebelo.pdf?resourceurlname=JorgeRebelo.pdf $>$. Acesso em: 19 de março de 2016.

SILVA, Moacir. Geografia dos Transportes no Brasil. Rio de Janeiro. Serviço Gráfico do Instituo Brasileiro de Geografia e Estatística, 1949.

SILVA, Júlio César L. Da. "A estratégia brasileira de privilegiar as rodovias em detrimento das ferrovias"; Brasil Escola. Disponível em: <http://brasilescola.uol.com.br/geografia/ por-que-brasil-adotou-utilizacao-das-rodovias-ao-inves-.htm>. Acesso em: 25 de setembro de 2016.

SOARES, Marcos. Multimodalidade e as Hidrovias no Brasil, 2009. <http://web.antaq. gov.br/Portal/pdf/Palestras/ForumHidrovias2009/Painel3/MarcosSoaresCNTFenavega. pdf $>$. Acesso em: 19 de março de 2017.

VACLAVIK, Marcia - C., MAÇADA, Antônio Carlos G., Análise da Viabilidade da Utilização da Cabotagem: um Estudo de Caso, setembro de 2009. Disponível em: $<$ http://www.anpad.org.br/admin/pdf/GOL2871.pdf >. Acesso em: 14 de setembro de 2016.

WORLD BANK, 2014. Disponível em: <http://lpi.worldbank.org/international/ scorecard/line/254/C/BRA/2014/C/BRA/2014? sort=asc\&order=Customs\#datatable . Acesso em: 19 de março de 2016. 
